
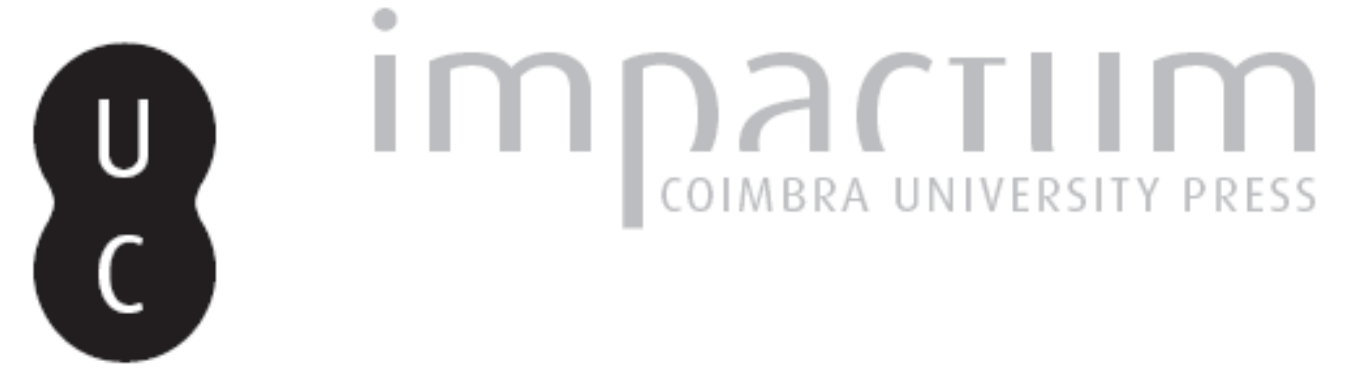

\title{
Ficaria na Galiza a cidade de Celtica Flavia?
}

\section{Autor(es): $\quad$ Alarcão, Jorge de}

Publicado por: Faculdade de Letras da Universidade de Coimbra

URL persistente:

URI:http://hdl.handle.net/10316.2/37857

DOI:

DOI:http://dx.doi.org/10.14195/1647-8657_49_1

Accessed : $\quad$ 26-Apr-2023 16:26:30

A navegação consulta e descarregamento dos títulos inseridos nas Bibliotecas Digitais UC Digitalis, UC Pombalina e UC Impactum, pressupõem a aceitação plena e sem reservas dos Termos e Condições de Uso destas Bibliotecas Digitais, disponíveis em https://digitalis.uc.pt/pt-pt/termos.

Conforme exposto nos referidos Termos e Condições de Uso, o descarregamento de títulos de acesso restrito requer uma licença válida de autorização devendo o utilizador aceder ao(s) documento(s) a partir de um endereço de IP da instituição detentora da supramencionada licença.

Ao utilizador é apenas permitido o descarregamento para uso pessoal, pelo que o emprego do(s) título(s) descarregado(s) para outro fim, designadamente comercial, carece de autorização do respetivo autor ou editor da obra.

Na medida em que todas as obras da UC Digitalis se encontram protegidas pelo Código do Direito de Autor e Direitos Conexos e demais legislação aplicável, toda a cópia, parcial ou total, deste documento, nos casos em que é legalmente admitida, deverá conter ou fazer-se acompanhar por este aviso.

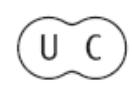


CONIMBRIGA

C)

CN N N

INSTITUTO DE ARQUEOLOGIA

VOLUME XLIX • 2010

FACULDADE DE LETRAS 
JoRge DE Alarcão

Professor Catedrático Aposentado da Faculdade de Letras de Coimbra

Membro do Centro de Estudos Arqueológicos das Universidades de Coimbra e Porto

FICARIA NA GALIZA A CIDADE DE CELTICA FLAVIA?

"Conimbriga" XLIX (2010) p. 7-14

RESUmo: O nome Celticoflaviensis, correspondente a uma civitas, encontra-se em duas inscrições funerárias de Astorga e da região de Salamanca. O autor sugere para esta civitas uma localização na Galiza, em território de Celtici Neri, Praestamarci ou Supertamarci.

RESUMÉ: Le nom Celticoflaviensis, correspondant à une civitas, se trouve dans deux inscriptions funéraires d' Astorga et de la région de Salamanque. L' auteur sugère pour cette civitas une situation dans l' actuelle Galice, en territoire de Celtici Neri, Praestamarci ou Supertamarci.

Conimbriga, 49 (2010) 7-14 
(Página deixada propositadamente em branco) 


\section{FICARIA NA GALIZA A CIDADE DE CELTICA FLAVIA?}

Duas inscrições romanas, uma achada em Aldea Tejada, a três quilómetros de Salamanca, e a outra em Astorga, mencionam Celticoflavienses. A primeira, publicada em CIL II 880, diz assim: DMS. Amme Festi f(iliae) Albocolensi an(norum) XXIII Cassius Vegetus Celticoflaviensis uxore piae f(aciendum) c(uravit). A segunda, dada a conhecer por Sónia M. ${ }^{a}$ García Martínez e Patrick Le Roux (1996), contém o seguinte texto: [...] Su[nu]ae f(ili-) an(norum) XXIII [Do] quirus Doci (filius) [Ce]lticoflavien(sis) de suo f(aciendum) c(uravit).

Testemunhando a existência de uma cidade Celtica Flavia (ou Celticum Flavium?), as duas inscrições põem dois problemas: a cidade chamar-se-ia só Celtica Flavia ou estes são cognomina, estando omitido o nome próprio da cidade? E onde ficaria tal cidade?

Não podendo, à partida, excluir a hipótese de a cidade ter, como nome próprio, o de Celtica, e de Flavia ser o cognomen que atestaria a sua promoção jurídica na época flaviana, manteremos, por enquanto, a dúvida e voltaremos mais abaixo ao assunto. Onde ficaria, porém, tal cidade?

Sónia M. ${ }^{a}$ García Martínez e Patrick Le Roux, observando que o antropónimo Doquirus se encontra com frequência nos distritos de Castelo Branco e Viseu, bem como na região de Trujillo (Cáceres), e que o nome Sunua se acha bem representado nos distritos de Viseu, Guarda, Castelo Branco e na província de Cáceres, sugeriram a localização de Celticum Flavium ou Celtica Flavia nesta vasta área, com preferência para as regiões de Viseu, Guarda ou Covilhã. Chamaram ainda a atenção para a fórmula de suof(aciendum) c(uravit), que, não sendo comum em inscrições funerárias, se encontra em Badajoz e Trujillo. Poderíamos acrescentar que também se regista em Egitania (SÁ, 2007, n. ${ }^{\text {os }} 113$, 138 e 195).

Conimbriga, 49 (2010) 7-14 
O nome de Sunua talvez se deva excluir como pista para a localização de Celtica Flavia. Com efeito, na inscrição de Astorga não se diz que Sunua era celticoflaviense. Esta naturalidade era a do dedicante, Doquirus, filho de Docus; e este pode ter erguido a lápide funerária a alguém (cujo nome ignoramos) que seria filho ou filha de uma Sunua não celticoflaviense. Quanto ao celticoflaviense de CIL II 880, o nome de Cassius Vegetus não dá qualquer pista utilizável para a localização da cidade. Docius (ou Docus) e Docia registam-se no distrito de Bragança e nas áreas de Astorga e Zamora, para além de Trujillo (ABASCAL PALAZÓN, 1994 e Atlas Antroponimico).

As duas inscrições em causa contêm ainda outra singularidade: em ambas são os dedicantes, e não as pessoas a quem as lápides foram dedicadas, que se declaram celticoflavienses. $O$ normal, quando se indica a origo em inscrições funerárias, é que ela seja a do indivíduo a quem se dedica a lápide. No distrito de Castelo Branco, só encontramos caso similar em Egitania, numa inscrição erguida a Valgia Flacilla por um M(arcus) Allacarius Paullianus, que se declara Conimbrigensis (SÁ, 2007, n. $\left.{ }^{\circ} 109\right)$. Mas não fizemos pesquisa nos distritos da Guarda ou Viseu, nem na área de Trujillo, até por duvidarmos de que este pormenor possa ser verdadeiramente significativo e contribua para ajudar-nos a esclarecer a situação de Celtica Flavia.

Sem rejeitarmos liminarmente a hipótese de localização proposta por Sónia M. ${ }^{a}$ García Martínez e Patrick Le Roux, que, à primeira vista, parece sensata, não deixaremos de observar que, sendo essa a localização de Celtica Flavia, devíamos encontrar o nome na inscrição da ponte de Alcântara, CIL II 760. Entre outros nomes, esta inscrição recorda exactamente as civitates que ficavam nas áreas da Covilhã, Guarda e Viseu.

Por outro lado, parece suspeita a existência de uma Celtica Flavia em área onde não temos atestada a presença de Celtici. É certo que Plínio 3, 13 diz que Celtici a Celtiberis ex Lusitania aduenisse manifestum est sacris, língua, oppidorum uocabilis quae cognominibus in Baetica distinguntur, "é evidente pela religião, pela língua e pelos nomes das cidades (as quais, na Bética, se distinguem pelos cognomes) que os Célticos procedem dos Celtiberos e vieram da Lusitânia". Pensando neste passo, poderíamos admitir uma Celtica Flavia na Betúria Céltica ou no Nordeste alentejano. 
Inés Sastre Pratts (2002: 108-109, nota 1) sugeriu a localização de Celtica Flavia na província de Salamanca. Não nos parece que a inscrição CIL II 880 possa fundamentar tal opinião.

Vamos considerar a hipótese de Celtica Flavia se localizar no extremo noroeste da Callaecia.

Se, em vez de nos centrarmos na onomástica pessoal, atentarmos no nome de Celtici (porque uma cidade Celtica Flavia ou Celticum Flavium seria normal em território de Celtici), logo nos ocorrem os Celtici do Noroeste.

Referindo-se a esta área, e depois de citar o Promontório Céltico, Plínio 4, 111 menciona os povos que aí viviam: Celtici cognomine Neri et Supertamarci, quorum in peninsula tres arae sestianae Augusto dicatae, Copori, oppidum Noeca, Celtici cognomine Praestamarci, Cileni, "os Célticos, por sobrenome Nérios e Supertamarcos, em cuja península ficam as três Aras Sestianas, dedicadas a Augusto; os Coporos, a povoação de Noega, os Célticos por sobrenome Prestamarcos e os Cilenos".

Mela III, 1, 11 refere os mesmos Neri, Praestamarci e Supertamarci, mas sem expressamente dizer que se trata de Celtici. Existe consenso, porém, em considerar que estes três populi eram Celtici, eventualmente vindos do sul, numa expedição ou invasão de que Estrabão III, 1, 3 e 5 deu notícia (TRANOY, 1981: 58-59).

Diz Mela: Partem qua prominet Praesamarci habitant perque eos Tamaris et Sars flumine non longe orta decurrunt Tamaris; secundum Ebora portum, Sars iuxta turrem Augusti titulo memorabilem cetera Supertamarici Nerique incolunt in eo tractu ultimi, hactenus enim ad Occidentem versa litora pertinent, "A parte que se eleva habitam-na os Prestamarcos e por entre eles desembocam o Tamaris e o Sars, rios que não nascem longe; o Tamaris termina detrás do mesmo porto de Ebora e o Sars perto da torre famosa por seu sobrenome de Augusta. Nas terras mais além vivem os Supertamarcos e os Nérios, os últimos deste sector, pois até aqui se estendem as terras voltadas a ocidente."

O Promontorium Celticum de Plínio, correspondente ao Nérion akrotérium de Ptolemeu, seria o cabo Touriñan, o Finisterra ou o Ortegal (GARCIA ALONSO, 2003: 143-144).

Em Astorga ou na sua região, algumas inscrições testemunham a emigração de Supertamarci para essa área (CIL II 2092=5667; CIL II 2904=5081; AE, 1976, n. ${ }^{\circ}$ 286; Hisp. Ep., 11, 2005, n. ${ }^{\circ} 281$ ).

Os Pestamarcos encontram-se ainda mencionados no Parochiale Suevum dos fins do séc. VI (aliás, com os Celticos), na versão do 
Liber Fidei da Sé de Braga (COSTA, 1965 e 1978, docs. n. ${ }^{\text {os }} 11$ e 551). Aparentemente, nestes documentos, tais nomes estão incluídos em interpolações muito tardias (do séc. XI?). Talvez nunca tenham existido como "paróquias" suevas e tenham sido retirados de fontes antigas por algum escriba ou notário erudito. Mas, pelo menos na segunda metade do séc. X, o nome Celtigos correspondia a uma realidade, pois se encontra em dois documentos do mosteiro de Celanova (ANDRADE, 1995, docs. n. ${ }^{\text {os }} 2$ e 478). Uma pesquisa sistemática da documentação altomedieval da Galiza descobriria certamente outras referências aos Celtigos, se não também a Prestamarcos e Supertamarcos.

Põe-se-nos o problema de saber se Celtici Neri, Celtici Praestamarci e Celtici Supertamarci terão sido (na época dos Flávios?) fundidos numa única civitas, eventualmente com capital em Celtica Flavia (ou Celticum Flavium) ou se cada um destes populi deu origem a uma civitas. Neste último caso, de que civitas seria Celtica Flavia a capital?

As inscrições de Astorga, que registam Supertamarci a par com Celticoflavienses, sugerem que devemos excluir a identificação de uns com outros. Os Supertamarci terão constituído uma civitas, designada por etnónimo, como o foram muitas outras civitates (designadamente as que figuram na inscrição da ponte de Alcântara). O oppidum que lhes terá servido de capital poderá ter tido, porém, nome próprio, sem relação com o etnónimo.

A ausência dos nomes Neri e Praestamarci em inscrições (ou a sua não atestação até agora) permite a hipótese de os dois populi terem sido fundidos numa única e mesma civitas, cuja capital seria exactamente Celtica Flavia. Mas também não podemos excluir a hipótese de os dois populi terem sido convertidos em duas civitates autónomas, uma das quais teria Celtica Flavia por capital.

Voltando ao Parochiale Suevum e aos documentos do mosteiro de Celanova, podemos admitir que os Celtigos eram os herdeiros dos antigos Celticoflavienses e que os Pestemarcos o eram dos antigos Praestamarci. A ausência do nome Nérios nesses documentos reforça a ideia de Neri e Praestamarci terem sido fundidos numa única civitas, com predominância dos segundos.

Mas onde poderia ficar, exactamente, Celtica Flavia?

O Itinerário de Antonino regista, na estrada de Bracara Augusta a Lucus Augusti, as seguintes estações viárias:

$\begin{array}{ll}\text { Aquis Celenis } & \text { CLXV MP } \\ \text { Vico Spacorum } & \text { CXCV Stadia }\end{array}$

Conimbriga, 49 (2010) 5-14 


$\begin{array}{ll}\text { Ad Duos Pontes } & \text { CL Stadia } \\ \text { Glandimiro } & \text { CLXXX Stadia } \\ \text { Atricondo } & \text { XXII MP } \\ \text { Brigantium } & \text { XXX MP }\end{array}$

Com excepção de Bracara Augusta (Braga), Aquis Celenis (Caldas de Reis) e Brigantium (Corunha), a identificação destes lugares é controversa (PÉREZ LOSADA: 2002; RODRÍGUEZ COLMENERO et alii: 2004; TIR, Hoja K 29: Porto).

Vico Spacorum, Ad Duos Pontes e Glandimiro terão sido povoações litorais, visto as distâncias serem dadas em stadia. Atricondo seria povoação ou estação viária interior.

Alguns manuscritos do Itinerário de Antonino registam Trigondo em vez de Atricondo. Admitindo, por hipótese, que Tricondo seja forma mais correcta, mas, ainda assim, deformada ou evoluída, teríamos um nome Tricondum, Tricondium ou Tricontium? O elemento Tri- exprimiria triplicidade? Teremos aqui povoação que, em algum tempo, foi lugar central dos três Célticos, Neri, Praestamarci e Supertamarci?

Os habitantes de Tricondum poderiam ser chamados Tricondini. Mas a consciência de que Tri- era prefixo pode, eventualmente, ter justificado que, em algum tempo, se tenha usado simplesmente o nome Condini. Este teria dado o de Contenos que surge, no Parochiale Suevum, como nome de uma paróquia da sé de Iria (DAVID, 1947: 42).

A hipótese de Tricondum ter sido Celtica Flavia talvez mereça consideração. Nesse caso, o nome completo seria Tricondum Celticum Flavium. Nas duas inscrições que recordam Celticoflavienses, ter-se-ia omitido o nome próprio da cidade.

Mesmo admitindo a hipótese de Tricondum ter funcionado, em algum tempo, como lugar central dos três Célticos do Noroeste, não podemos, porém, deixar de admitir também a hipótese de Celtica Flavia ou Celticum Flavium não ter sido cognome de Tricondum e ter ficado noutro lugar do Noroeste.

Admitindo que Celtica Flavia ficaria no extremo noroeste da Galiza, não podemos, porém, ignorar que o antropónimo Doquirus só foi, até agora, registado numa única inscrição dessa província (PEREIRA MENAUT, 1991: $\mathrm{n}^{\circ} 28$ ). Mas será isso suficiente argumento para contrariar a localização que propomos? 


\section{REFERÊNCIAS}

ABASCAL PALAZÓN, Juan Manuel (1994) - Los nombres personales en las inscripciones latinas de Hispania. Múrcia: Universidad

ANDRADE, José M. (1995) - O Tombo de Celanova. Santiago de Compostela: Consello da Cultura Galega

Atlas Antroponimico = Atlas antroponímico de la Lusitania romana. Mérida: Fundación de Estudios Romanos/ Bordéus: Ausonius Editions, 2003

COSTA, Avelino de Jesus da (1965 e 1978) - Liber Fidei Sanctae Bracarensis Ecclesiae. Tomo I (1965) e II (1978). Braga: Junta Distrital de Braga

DAVID, Pierre (1947): Études historiques sur la Galice et le Portugal du $V^{\mathrm{e}}$ au XI siècle. Lisboa: Livraria Portugal/ Paris: Les Belles-Lettres

GARCÍA ALONSO, Juan L. (2003) - La Península Ibérica en la Geografia de Claudio Ptolomeo. Vitória/Gasteiz: Universidad del País Vasco

GARCÍA MARTÍNEZ, Sónia M. ${ }^{a}$ e LE ROUX, Patrick (1996) - "Un nuevo testimonio sobre Celticum Flavium en Asturica Augusta (Astorga, León)". Conimbriga, Coimbra, v. 35: 59-67

GARCÍA MARTÍNEZ, Sónia M.a - "Una Celtica Supertamarca en Andiñuela (León)", Conimbriga, 36 (1997): 95-101

PEREIRA MENAUT, Gerardo (1991) - Corpus de inscripcións romanas de Galicia. I. Província de A Coruña. Santiago de Compostela

PÉREZ LOSADA, Fermín (2002) - Entre a cidade e a aldea. Estudo arqueohistórico dos "aglomerados secundários" romanos en Galicia. Corunha (= Brigantium, 13)

RODRÍGUEZ COLMENERO, António et alii (2002) - Miliários e outras inscricións viárias romanas del Noroeste hispânico. Santiago de Compostela: Consello da Cultura Galega

SÁ, Ana Marques de (2007): Civitas Igaeditanorum. Os deuses e os homens. Idanhaa-Nova: Câmara Municipal

SASTRE PRATTS, Inés (2002) - Onomástica y relaciones politicas en la epigrafia del conventus Asturum durante el Alto Império. Madrid: Consejo Superior de Investigaciones Científicas (= Anejos de Archivo Español de Arqueologia)

TIR = Tabula Imperii Romani. Hoja K-29: Porto. Madrid: Consejo Superior de Investigaciones Científicas

TRANOY, Alain (1981) - La Galice romaine. Recherches sur le nord-ouest de la peninsule ibérique dans l'Antiquité. Paris: Éditions De Boccard

Conimbriga, 49 (2010) 5-14 